\title{
Type 0: Not a Combination Product
}

National Cancer Institute

\section{Source}

National Cancer Institute. Type 0: Not a Combination Product. NCI Thesaurus. Code C112160.

A designation assigned when a product is not manufactured as a combination product. 